\title{
FORMULATION AND EVALUATION OF ORODISPERSIBLE TABLETS OF A MODEL ANTI- HYPERTENSIVE DRUG
}

\author{
S. P. HIREMATH* , CHIDAMBAR MAKANAPUR \\ Department of Pharmaceutics, KLE University's College of Pharmacy, Hubli 580031, Karnataka, India \\ Email: hiremathsp2005@gmail.com
}

Received: 06 Apr 2017 Revised and Accepted: 21 Sep 2017

\section{ABSTRACT}

Objective: The rationale of the current work was to formulate and evaluate orodispersible tablets by direct compression technique with a vision to augment patient compliance and rapid onset of action.

Methods: Nine orodispersible formulations of propranolol were formulated by direct compression method using sodium starch glycolate, crospovidone and croscarmellose sodium as the super disintegrants. The prepared formulations were evaluated for wetting time, drug content, in vitro disintegration time, dispersion time, dissolution time and also projected to kinetic treatment to know the pattern of drug release. Further, the discovered promising formulation was subjected to stability studies.

Results: Based on the results obtained, formulation F9 containing 6 mg of croscarmellose sodium exhibited good wetting time, dispersion time, and disintegration time and drug release compared to orodispersible tablets prepared with other super disintegrants. The stability studies piloted as per International Conference on Harmonisation guidelines on the promising formulationF9disclosedno significant changes in the colour (white), drug content $(94.87 \pm 0.141 \mathrm{mg})$, hardness $\left(2.93 \pm 0.18 \mathrm{~kg} / \mathrm{cm}^{2}\right)$, disintegration time $(17.11 \pm 0.089 \mathrm{~s})$, and drug release after $4 \mathrm{w}$. After $60 \mathrm{~s}$, the percentage drug release of F9 was found to be $98.52 \%$ and $96.30 \%$ after 1 and $4 \mathrm{w}$, respectively.

Conclusion: Orodispersible tablets of propranolol hydrochloride were formulated successfully by employing direct compression technique. From the investigation, it can be reasonably concluded that F9 batch orodispersible tablets of propranolol with 6 mg of crospovidone exhibited maximum cumulative drug release in $60 \mathrm{~s}$.

Keywords: Propranolol, Orodispersible tablets, Direct compression technique, Superdisintegrants

(C) 2017 The Authors. Published by Innovare Academic Sciences Pvt Ltd. This is an open-access article under the CC BY license (http://creativecommons.org/licenses/by/4.0/) DOI: http://dx.doi.org/10.22159/ijpps.2017v9i11.18967

\section{INTRODUCTION}

Oral dosage forms, both the solids and liquids, have been the most extensively accepted routes of drug delivery for decades now. It is widely accepted because of its advantages such as self-medication, ease of administration, pain avoidance, and patient compliance $[1,2]$. However, the evident shortcomings of this route are difficulty in swallowing and patient noncompliance, especially in paediatric geriatric, nauseated, and mentally ill patients $[3,4]$. All these restraints could be resolved by one of the recent pioneering advances in novel drug delivery system (NDDS) - by orally disintegrating tablets (ODT).

ODT technology has been recently approved by the United States Pharmacopoeia (USP) and Centre for Drug Evaluation and Research (CDER) [4]. As perUnited States Food and Drug Administration (USFDA), ODT is a solid dosage form comprising medicinal constituent, which instantaneously dissipates within seconds into the saliva when kept on the tongue [5]. The drug will be absorbed as the saliva gradually passes down from the mouth, pharynx, oesophagus, and stomach [6].

The principal benefits of ODT include meliorated patient compliance, improved bioavailability, rapid onset of action, pain avoidance, consumption without water, pregastric absorption, versatility, and economical [7-9]. Pregastric absorption is the major capital advantage of the ODTs, which avoids hepatic first-pass metabolism of the drugs [10].

Propranolol, a nonselective beta blocker, is used to treat major disorders such as acute myocardial infarction, angina pectoris, arrhythmias, hypertension, hyperthyroidism, hypertensive emergencies, menopause, pheochromocytoma, migraine, and anxiety [11]. Propranolol hydrochloride competes with the sympathomimetic neurotransmitters and prevents the binding of catecholamines at beta (1)-adrenergic receptors present in the heart. This results in a decrease of diastolic and systolic and blood pressure, cardiac output, and reflex orthostatic hypotension [11]

The present work was attempted to develop an orodispersible antihypertensive tablet, which dissipates instantaneously in the oral cavity within few seconds without the aid of water. This will enhance the dissolution rate and bioavailability along with the rapid onset of pharmacological action. In the current development, the ODTs of propranolol were formulated by direct compression technique using crospovidone, sodium starch glycolate and croscarmellose sodium, as the super disintegrants to augment patient compliance and rapid onset of action.

\section{MATERIALS AND METHODS}

The active pharmaceutical ingredient-propranolol hydrochloride was procured from Micro labs, Bengaluru. The other excipients such as magnesium stearate, purified talc, and mannitol were procured from SD Fine Chemicals (Mumbai). Sodium starch glycolate and croscarmellose sodium were purchased from Maruthi Chemicals Ltd. (Ahmedabad), and crospovidone was purchased from Kawarlal excipients (P) Ltd (Chennai). Microcrystalline cellulose pH 102 was purchased from Elegant pharmaceuticals (Hubli). Aspartame was purchased from Nutra Sweet Company.

\section{Formulation of orodispersible tablets}

Orodispersible tablets of propranolol were formulated by the direct compression technique. The details of composition for the formulations are mentioned in table 1 . All the ingredients except talc and magnesium stearate were weighed accordingly and mixed thoroughly to ensure proper mixing of drug with the super disintegrants. The mixture was sifted through a sieve no. 40 and then blended with talc and magnesium stearate. Finally, the blended mixture was subjected to compression using rimek tablet punching machine using $6.5 \mathrm{~mm}$ flat and circular punch. 
Table 1: The quantity of ingredients for the designed formulations of propranolol orodispersible tablets by direct compression technique

\begin{tabular}{|c|c|c|c|c|c|c|c|c|c|}
\hline \multirow[t]{2}{*}{ Ingredients } & \multicolumn{9}{|c|}{ Composition (mg) } \\
\hline & F1 & F2 & F3 & F4 & F5 & F6 & F7 & F8 & F9 \\
\hline Propranolol HCl & 40 & 40 & 40 & 40 & 40 & 40 & 40 & 40 & 40 \\
\hline Sodium starch glycolate & 3.6 & 4.8 & 6 & - & - & - & - & - & - \\
\hline Croscarmellose sodium & - & - & - & 3.6 & 4.8 & 6 & - & - & - \\
\hline Crospovidone & - & - & - & - & - & - & 3.6 & 4.8 & 6 \\
\hline Mannitol & 24 & 24 & 24 & 24 & 24 & 24 & 24 & 24 & 24 \\
\hline Microcrystalline cellulose pH102 & 47.6 & 46.4 & 45.2 & 47.6 & 46.4 & 45.2 & 47.6 & 46.4 & 45.2 \\
\hline Aspartame & 1.2 & 1.2 & 1.2 & 1.2 & 1.2 & 1.2 & 1.2 & 1.2 & 1.2 \\
\hline Purified talc & 1.2 & 1.2 & 1.2 & 1.2 & 1.2 & 1.2 & 1.2 & 1.2 & 1.2 \\
\hline Magnesium stearate & 2.4 & 2.4 & 2.4 & 2.4 & 2.4 & 2.4 & 2.4 & 2.4 & 2.4 \\
\hline Total weight & 120 & 120 & 120 & 120 & 120 & 120 & 120 & 120 & 120 \\
\hline
\end{tabular}

HCl: Hydrochloride

\section{Evaluation of orodispersible tablets}

The formulated ODTs were evaluated for physiochemical parameters such as general appearance, weight variation test, uniformity of thickness, friability test, hardness test, and drug content uniformity. The other key parameters which were especially evaluated are following:

\section{Drug content}

Five tablets from each formulation were randomly selected, accurately weighed, and average weight per tablet was calculated. Each tablet was pulverized to a very fine powder and a known amount of drug that is equivalent to $40 \mathrm{mg}$ of propranolol hydrochloride was transferred into a $100-\mathrm{ml}$ volumetric flask. Phosphate buffer ( $6.8 \mathrm{pH})$ was used to dissolve the drug and solution was made up to the mark. The solution was strained and from which $1 \mathrm{ml}$ was withdrawn into a $10-\mathrm{ml}$ volumetric flask and diluted with buffer. The resultant solution was determined spectrophotometrically at $290 \mathrm{~nm}$ [12].

\section{Wetting time}

Wetting time was performed to determine the disintegration properties of the tablet. Lower wetting time indicates a faster disintegration of the tablet. A section of tissue paper of $10.75 \mathrm{~cm}$ diameter was folded twice and placed in a petri dish containing $10 \mathrm{ml}$ of water. An ODT was placed carefully on the surface of butter paper and the time consumed for complete wetting was taken as a wetting time [13].

\section{In vitro dispersion time}

The dispersion time was determined by dropping an ODT in a measuring cylinder having $50 \mathrm{ml}$ of simulated saliva fluid of $\mathrm{pH}$ of 6.8. Three tablets from each batch were selected arbitrarily and in vitro dispersion time was measured [14].

\section{In vitro disintegration time}

The disintegration time of ODT was determined by disintegration apparatus as per Indian Pharmacopoeia (IP) specifications. Each ODT was placed in six tubes of the basket and a disc was placed in all six tubes to prevent the floating of tablets. The simulated saliva, fluid of $\mathrm{pH} 6.8$, maintained at $37( \pm 2)^{\circ} \mathrm{C}$, was used as an immersion liquid. The whole assembly placed in immersion liquid was raised and lowered at 30 cycles/min frequency. The time taken for the complete disintegration of ODT with no residue remaining in the apparatus was recorded $[15,16]$.

\section{In vitro dissolution studies}

The dissolution studies of ODT were accomplished using United States Pharmacopeia (USP) XXIV type II paddle type dissolution apparatus at $50 \mathrm{rpm}$. The release profile of the drugs was studied in $900 \mathrm{ml}$ of $0.1 \mathrm{~N}$ hydrochloric acid buffer of $\mathrm{pH} 1.2$ or phosphate buffer of $\mathrm{pH} 6.8$ maintained at temperature $37 \pm 0.5^{\circ} \mathrm{C}$. For every $30 \mathrm{~s}, 2 \mathrm{ml}$ of the aliquots was withdrawn, filtered, diluted suitably; and the amount of the drug release was determined spectrophotometrically at $290 \mathrm{~nm}$. After the each withdrawal, the same volume replaced into the apparatus to keep the sink conditions [17-20].

\section{Release kinetics}

The cumulative drug release data obtained from formulations were subjected to different kinetic models such as zero-order kinetics, first-order kinetics, higuchi model, and Korsmeyer-peppas release model [21-23].

Zero-order kinetic model: $\mathrm{C}=\mathrm{K}_{0} \mathrm{t}$

Where, $\mathrm{K}_{0}=$ zero-order rate constant (concentration/time)

$\mathrm{t}=$ time

First-order kinetic model: $\log C=\log C 0-K_{1} t / 2.303$

Where $\mathrm{C}_{0}=$ initial drug concentration and $\mathrm{K}_{1}$ is first-order constant

Higuchi model: $\mathrm{f}_{\mathrm{t}}=\mathrm{K}_{\mathrm{H}} \mathrm{t}^{1 / 2}$

Where, $\mathrm{f}_{\mathrm{t}}=$ amount of drug released in time $\mathrm{t}$

$\mathrm{K}_{\mathrm{H}}=$ Higuchi dissociation constant

Korsmeyer-peppas model: $\mathrm{M}_{\mathrm{t}} / \mathrm{M}_{\infty}=\mathrm{Kt}^{\mathrm{n}}$

Where $\mathrm{Mt} / \mathrm{M} \infty=$ fraction of drug release

$\mathrm{K}=$ drug release constant

$\mathrm{t}=$ release time

$\mathrm{n}=$ diffusion coefficient, which characterizes the drug release, depends on the shape of the matrix dosage form.

Hixson-Crowell model: $\mathrm{W}_{0}^{1 / 3}-\mathrm{W}_{\mathrm{t}^{1 / 3}}=\kappa \mathrm{t}$

Where, $\mathrm{W}_{0}=$ initial amount of drug in the formulation

$\mathrm{W}_{\mathrm{t}}$ =amount of drug remained in the formulation after time ' $\mathrm{t}$ '

$\mathrm{K}=$ constant incorporating surface-volume relation

\section{Stability studies}

The stability studies for the promising formulation were executed based on International Conference on Harmonisation (ICH) guidelines. The promising ODT was subjected to $40 \pm 2{ }^{\circ} \mathrm{C}$ and $75 \pm 5 \%$ relative humidity for $30 \mathrm{~d}$. After the specific period is finished, the ODT was once again subjected to all the tests to determine any variance in colour, hardness, drug content uniformity, \% cumulative drug release (CDR), in vitro disintegration time [8].

\section{RESULTS AND DISCUSSION}

Oral drug delivery, one of the most frontier zones of drug delivery system, has a major benefit of patient compliance. The ODTs belong to the category of oral drug delivery disintegrates and release the medicament rapidly in the oral cavity. The release rate of the drug chiefly depends upon the type and concentration of the super disintegrants, which swell and lead to rapid wicking or bursting of the drug.

In the current investigation, an attempt has been made to formulate and evaluate ODTs of propranolol hydrochloride used in the 
management of hypertension. The ODTs were formulated by direct compression technique using super disintegrants-sodium starch glycolate, croscarmellose sodium, crospovidone, and other additives.

\section{Wetting time}

The tablet, when placed in the saliva, mimics the action of it and lead to water uptake and subsequent wetting of the tablet. The wetting time depends on the inner structure of ODT. Since the dissolution process of ODT depends upon the wetting time, followed by disintegration time it could be expected that wetting time might be the cause of disintegration [24]. The wetting time of the formulations was observed to be in the range of $28.71 \pm 0.986$ to $76.47 \pm 2.093 \mathrm{~s}$. It was observed that wetting time was very rapid in crospovidone followed by croscarmellose sodium and the sodium starch glycolate (table 2).

\section{Drug content}

The drug content uniformity was executed for all the nine formulations and results are tabulated in table 2. The drug content of the ODTs was found to be in the range of $93.87 \pm 0.015$ to $99.87 \pm 0.013 \mathrm{mg}$. The results obtained were within the Pharmacopeial limits and indicated uniformity of mixing. The in-vitro release studies showed that the cumulative percentage drug released by each ODT was based on the average drug content of the tablet [25].

\section{In vitro dispersion time}

The dispersion time is a parameter, which was executed to determine the time period taken for the ODT to undergo complete dispersion. The dispersion time for the nine formulations was varied within the range of $25.09 \pm 1.313$ to $63.88 \pm 1.186 \mathrm{~s}$. Among these, formulation F9 containing $6 \mathrm{mg}$ crospovidone exhibited faster dispersion. The quicker disintegration of crospovidone ODTs may be due to its fast capillary activity [26]. The corresponding results were shown in table 2. Among all formulations, in vitro dispersion was fast in crospovidone followed by croscarmellose sodium and Sodium starch glycolate [14].

\section{In vitro disintegration time}

The disintegration time of the formulations was varied from $18.65 \pm 0.680$ to $55.13 \pm 1.160$ s. The formulations with crospovidone exhibited rapid drug disintegration pursued by croscarmellose sodium and sodium starch glycolate. The rapid disintegration is due to prompt uptake of water from dissolution medium, bulging, and burst effect. Moreover, it was noted that as the concentration of super disintegrant increases the time consumed for disintegration was decreased [14]. The corresponding disintegration times for each formulation at predetermined times were shown in table 2 .

Table 2: Drug content uniformity, in vitro disintegration time, dispersion time, and wetting time of formulations of F1-F9

\begin{tabular}{llll}
\hline $\begin{array}{l}\text { Formulation } \\
\text { code }\end{array}$ & $\begin{array}{l}\text { Drug content }(\mathrm{mg}) \\
\text { uniformity }\end{array}$ & $\begin{array}{l}\text { In vitro dispersion time in } \\
\text { seconds }\end{array}$ & $\begin{array}{l}\text { In vitro disintegration time in } \\
\text { seconds }\end{array}$ \\
\hline F1 & $95.37 \pm 0.088$ & $63.88 \pm 1.186$ & $55.13 \pm 1.160$ \\
F2 & $96.87 \pm 0.125$ & $56.82 \pm 0.740$ & $45.50 \pm 1.523$ \\
F3 & $98.87 \pm 1.016$ & $48.26 \pm 0.890$ & $33.62 \pm 1.670$ \\
F4 & $99.37 \pm 0.013$ & $47.15 \pm 1.770$ & $36.25 \pm 1.280$ \\
F5 & $93.87 \pm 0.015$ & $41.86 \pm 1.040$ & $31.94 \pm 1.110$ \\
F6 & $98.37 \pm 0.054$ & $37.61 \pm 0.753$ & $25.09 \pm 1.296$ \\
F7 & $98.87 \pm 0.026$ & $38.20 \pm 1.010$ & $32.17 \pm 1.144$ \\
F8 & $99.87 \pm 0.013$ & $32.07 \pm 0.970$ & $24.16 \pm 1.086$ \\
F9 & $97.37 \pm 0.032$ & $25.09 \pm 1.313$ & $18.65 \pm 0.680$ \\
\hline
\end{tabular}

Data expressed in mean $\pm S D$, $(n=3)$

\section{In vitro dissolution studies}

Superdisintegrants accelerates the disintegration of the tablet by their ability to imbibe large amounts of water when exposed to an aqueous environment. The absorption of water consequences in breaking of tablets and consequently faster disintegration. This disintegration is stated to have an effect on dissolution characteristics as well. Formulated ODTs gets dispersed in the mouth rapidly and releases the drug early as compared to its prepared conventional tablets [27]. The data obtained from the dissolution studies disclosed that as the concentration of super disintegrant increases the percentage of drug release was also increases. The rapid breakdown and absorption of the particles in the dissolution medium were mainly due to the concentration of super disintegrant. Among all formulations, F9 formulated with $6 \mathrm{mg}$ of crospovidone exhibited $98.96 \%$ cumulative drug release in 60 s.

In addition, the drug release profile from all formulations was observed to be concentration dependent [27]. Including this, formulationF9 also showed short wetting time, good drug content, and fast disintegration. The corresponding drug release pattern of each formulation at predetermined intervals is shown in table 3 and 4 .

Table 3: In vitro dissolution profile of the formulations F4-F9

\begin{tabular}{lllll}
\hline Time (s) & \% CDR & & & F3 \\
\cline { 2 - 4 } & F1 & F2 & 0 & \\
\hline 0 & 0 & $49.69 \pm 0.922$ & $51.02 \pm 0.912$ \\
30 & $38.62 \pm 0.982$ & $64.38 \pm 0.978$ & $65.71 \pm 0.943$ & $43.49 \pm 0.988$ \\
60 & $43.09 \pm 0.992$ & $71.47 \pm 0.988$ & $84.33 \pm 0.985$ & $65.26 \pm 0.962$ \\
90 & $63.05 \pm 0.986$ & $83.05 \pm 0.963$ & $91.87 \pm 0.923$ & $93.02 \pm 0.977$ \\
120 & $70.14 \pm 0.896$ & $90.98 \pm 0.956$ & - & - \\
150 & $82.56 \pm 0.943$ & - & - & - \\
180 & $89.21 \pm 0.967$ & & & \\
\hline
\end{tabular}

CDR: Cumulative drug release; F: Formulation; Data expressed in mean $\pm \mathrm{SD},(\mathrm{n}=3)$

\section{Release kinetics}

The kinetic release data attained for the promising formulation was projected to kinetic treatment to determine the drug release order.
The data obtained from different models-zero-order kinetics, firstorder kinetics, higuchi, hixson crowell, and korsmeyer-peppas models disclosed that the promising formulation exhibited korsmeyer-peppas as the best fitting model (table 4). 
Table 4: In vitro dissolution profile of the formulations F5-F9

\begin{tabular}{|c|c|c|c|c|c|}
\hline \multirow[t]{2}{*}{ Time (s) } & \multicolumn{5}{|l|}{$\%$ CDR } \\
\hline & F5 & F6 & F7 & F8 & F9 \\
\hline 0 & 0 & 0 & 0 & 0 & 0 \\
\hline 30 & $53.23 \pm 0.912$ & $55.01 \pm 0.910$ & $56.33 \pm 0.933$ & $66.08 \pm 0.917$ & $88.28 \pm 0.914$ \\
\hline 60 & $74.13 \pm 0.895$ & $75.02 \pm 0.897$ & $76.79 \pm 0.966$ & $87.43 \pm 0.893$ & $98.96 \pm 0.925$ \\
\hline 90 & $94.09 \pm 0.911$ & $94.97 \pm 0.912$ & $87.88 \pm 0.918$ & $97.19 \pm 0.931$ & - \\
\hline 120 & - & - & $95.86 \pm 0.898$ & - & - \\
\hline 150 & - & - & - & - & - \\
\hline 180 & - & - & - & - & - \\
\hline
\end{tabular}

CDR: Cumulative drug release; F: Formulation; Data expressed in mean $\pm S D,(n=3)$

Table 4: Curve fitting data of the release rate profile of formulations F1-F9

\begin{tabular}{|c|c|c|c|c|c|c|c|c|c|c|c|c|}
\hline \multirow[t]{2}{*}{ Formulation } & \multicolumn{2}{|c|}{ Zero-order } & \multicolumn{2}{|c|}{ First order } & \multicolumn{2}{|c|}{ Higuchi } & \multicolumn{3}{|c|}{ Korsmeyer-peppas } & \multicolumn{2}{|c|}{ Hixon-crowell } & \multirow[t]{2}{*}{ Best fitting model } \\
\hline & $\mathbf{R}$ & $\mathbf{k}$ & $\mathbf{R}$ & $\mathbf{k}$ & $\mathbf{R}$ & $\mathbf{k}$ & $\mathbf{R}$ & $\mathbf{k}$ & $\mathbf{n}$ & $\mathbf{R}$ & $\mathbf{k}$ & \\
\hline F1 & 0.755 & 0.024 & 0.541 & -0.0001 & 0.934 & 0.061 & 0.974 & 0.146 & 0.146 & 0.622 & -0.0002 & Peppas \\
\hline $\mathrm{F} 2$ & 0.777 & 0.031 & 0.744 & -0.0000 & 0.923 & 0.058 & 0.982 & 0.157 & 0.131 & 0.544 & -0.0003 & Peppas \\
\hline F3 & 0.840 & 0.054 & 0.766 & -0.0005 & 0.936 & 0.095 & 0.967 & 0.121 & 0.253 & 0.659 & -0.0003 & Peppas \\
\hline F4 & 0.830 & 0.034 & 0.814 & -0.0003 & 0.978 & 0.148 & 0.999 & 0.162 & 0.275 & 0.755 & -0.0002 & Peppas \\
\hline F5 & 0.885 & 0.062 & 0.835 & -0.0002 & 0.924 & 0.135 & 0.992 & 0.168 & 0.217 & 0.537 & -0.0001 & Peppas \\
\hline F6 & 0.732 & 0.084 & 0.611 & -0.0006 & 0.951 & 0.147 & 0.989 & 0.207 & 0.194 & 0.621 & -0.0002 & Peppas \\
\hline F7 & 0.716 & 0.049 & 0.425 & -0.0002 & 0.949 & 0.1054 & 0.9591 & 0.152 & 0.372 & 0.825 & -0.0000 & Peppas \\
\hline F8 & 0.833 & 0.142 & 0.875 & -0.0015 & 0.963 & 0.1643 & 0.9997 & 0.196 & 0.291 & 0.757 & -0.0005 & Peppas \\
\hline F9 & 0.841 & 0.092 & 0.735 & -0.0007 & 0.937 & 0.1364 & 0.9979 & 0.132 & 0.109 & 0.533 & -0.0003 & Peppas \\
\hline
\end{tabular}

* $\mathrm{R}$ is drug release; $\mathrm{k}$ is rate constant for each model; $\mathrm{n}$ is diffusion coefficient; $\mathrm{F}$ : Formulation

\section{Stability studies}

Stability studies were conducted as per the ICH guidelines. The promising formulationF9 subjected to $40 \pm 2^{\circ} \mathrm{C} / 75 \pm 5 \% \mathrm{RH}$ for $1 \mathrm{mo}$ disclosed that there was no any significant changes in the colour, hardness, drug content uniformity, \% CDR, and in vitro disintegration time. It specifies that prepared optimized formulation is stable [28]. The corresponding results are shown in the table 5.

Table 5: Stability studies of promising formulation F9

\begin{tabular}{|c|c|c|c|c|c|}
\hline \multirow[t]{2}{*}{ Time } & \multicolumn{5}{|c|}{ Evaluation parameters } \\
\hline & Colour & Hardness $\left(\mathrm{kg} / \mathrm{cm}^{2}\right)$ & Drug content Uniformity(mg) & In vitro disintegration time & \% CDR \\
\hline After $1 \mathrm{w}$ & White & $3.19 \pm 0.23$ & $96.87 \pm 0.151$ & $18.41 \pm 1.027$ & 98.52 \\
\hline After $2 \mathrm{w}$ & White & $3.12 \pm 0.13$ & $96.37 \pm 0.112$ & $18.35 \pm 0.927$ & 98.08 \\
\hline After $3 \mathrm{w}$ & White & $3.04 \pm 0.08$ & $95.37 \pm 0.131$ & $17.25 \pm 1.011$ & 97.19 \\
\hline After $4 \mathrm{w}$ & White & $2.93 \pm 0.18$ & $94.87 \pm 0.141$ & $17.11 \pm 0.089$ & 96.30 \\
\hline
\end{tabular}

Data expressed in mean $\pm \mathrm{SD}$, $(\mathrm{n}=3)$; CDR: Cumulative drug release

\section{CONCLUSION}

In the current efforts have been made to formulate and evaluate orodispersible tablets of propranolol hydrochloride using different super disintegrants by a direct compression method. The results disclosed that increased amount of various super disintegrants were associated with an increase in overall rate of cumulative drug release. Of all nine formulations, F9 formulation with $6 \mathrm{mg}$ of crospovidone exhibited maximum cumulative drug release in $60 \mathrm{~s}$. In addition, formulation F9 also showed short wetting time, good drug content, and fast disintegration and followed korsmayer-peppas, as an ideal fitting model. Stability studies conducted also revealed no any significant changes in the colour, hardness, drug content uniformity, \% $\mathrm{CDR}$, and in vitro disintegration time. Henceforth, we concluded that formulated propranolol hydrochloride ODTs can be one of the better choices for the management of hypertension enhanced patient compliance and rapid onset of action.

\section{ACKNOWLEDGEMENT}

None

\section{AUTHOR CONTRIBUTION}

SPH designed the study and prepared the manuscript. CM developed and analysed the data and prepared the initial draft of the manuscript.

\section{CONFLICT OF INTERESTS}

The Author(s) declare(s) that they have no conflicts of interest to disclose

\section{REFERENCES}

1. Dey P, Maiti S. Orodispersible tablets: a new trend in drug delivery. J Nat Sci Biol Med 2010;1:2-5.

2. Nagar P, Singh K, Chauhan I, Verma M. Orally disintegrating tablets: formulation, preparation techniques and evaluation. J Appl Pharm Sci 2011;1:35-45.

3. Swamy N, Sachin, Abbas Z. Design and characterization of oral dispersible tablets of enalapril maleate using a co-processed excipient. J Appl Pharm Sci 2012;2:40-9.

4. Hirani JJ, Rathod DA, Vadalia KR. Orally disintegrating tablets: a review. Trop J Pharm Res 2009;8:161.

5. Abhay A, Swati A, Gayti A. Oral dispersible tablets: novel technology and development. Int J Pharm Sci Rev Res 2013;20:193-9.

6. Velmurugan S, Sundar V. Oral disintegrating tablets: an overview. Int J Pharm Chem Sci 2010;1:1-12.

7. Ibrahim HK, El-Setouhy DA. Valsartan orodispersible tablets: formulation, in vitro/in vivo characterization. AAPS PharmSciTech 2010;11:189-96.

8. Revathi S, Moulali SK, Dhanaraju MD. Formulation and evaluation of orodispersible valsartan tablets. Pharm Lett 2015;7:315-24. 
9. Rewar S, Singh C, Bansal B, Pareek R, Sharma A. Oral dispersible tablets: An overview; development, technologies and evaluation. Int J Res Dev Pharm Life Sci 2014;3:1223-35.

10. Deshpande K, Ganesh N. Orodispersible tablets: an overview of formulation and technology. Int J Pharma Biol Sci 2011;2:726-34.

11. Sivaramaiah N, Alekhya M, Anusha M, Bhargav C, Harish G. Formulation and evaluation of oral dispersible tablets of propranolol hcl. Am J Biol Pharm Res 2014;1:160-9.

12. Mohsin A, Nimbalakr NE, Sanaullah S, Aejaz A. Formulation and evalution of mouth dissolving tablets of amitriptyline hydrochloride by direct compression technique. Int J Pharm Pharm Sci 2010;2:204-10.

13. Goyani SM, Shah P, Vyas B, Shah D. Formulation and evaluation of orally disintegrating tablets of meclizine hydrochloride. Int Res J Pharm 2012;3:196-9.

14. Leela MK, Ramana G, Digpati R. Formulation and evaluation of oral disintegrated tablets of alfuzosin hydrochloride using super disintegrants. J Appl Pharm Sci 2011;1:161-5.

15. Vijaya K, Mishra D. Rapidly disintegrating oral tablets of meloxicam. Indian Drugs 2006;43:117 -21.

16. Hirave R, Kondawar M. Development and evaluation of herbal fast dissolving tablet of capparis divaricata lam. Int J Adv Pharma 2017;6:24-30.

17. Sai PB, Syamala S, Vinod kN, Voleti VK, Madhusudhan C Formulation and evaluation of orodispersible tablets of clonazepam using natural super disintegrants. IOSR-J Pharm Biol Sci 2014;9:47-52.

18. Dash S, Murthy PN, Nath L, Chowdhury P. Kinetic modeling on drug release from controlled drug delivery systems. Acta Pol Pharm 2010;67:217-23.
19. Gupta M, Vishal P. Formulation and evaluation oral dispersible tablets of cinnarizine. J Drug Delivery Ther 2013;3:12-7.

20. Karthik N, Vijaya KB, Sateesh KV. Different techniques to enhance the dissolution rate of lovastatin: formulation and evaluation. Asian J Pharm Clin Res 2013;6:56-60.

21. Reddy MNK, Hussain MA, Rao TR, Kishna TR, Pavan V. Formulation and evaluation of naproxen oral disintegraing tablets. Int J Pharm Biol Sci 2012;2:303-16

22. Costa P, Sousa Lobo JM. Modeling and comparison of dissolution profiles. Eur J Pharm Sci 2001;13:123-33.

23. Sumit D, Sayantan M, Laxmi G. Preparation, characterization and evaluation of floating microparticles of ciprofloxacin. Int J Appl Pharm 2017;9:1-8.

24. Shashank C, Vipin KA, Anurag V, Navneet V, Sunil S. Comparative evaluation of natural and semisynthetic super disintegrants in the formulation of orodispersible tablets of norfloxacin. Int J Pharm Pharma Sci 2012;4:576-83.

25. Ananda K, Kiran KT, Gyana JR. Development, formulation and evaluation of solifinacin succinate immediate release oral tablets by using starch and hpmc. Int J Res Pharm Nano Sci 2013;2:91-100.

26. Mangesh MS, Nagesh ST. Formulation and in vitro evaluation of fast dissolving tablets of metoprolol tartrate. Braz J Pharm Sci 2013;49:784-92.

27. Chandrasekhar P, Shahid MS, Niranjan BM. Formulation and evaluation of oral dispersible tablets of antihypertensive drug atenolol. Int J Pharm 2013;3:79-84.

28. Parag P, Tejal P, Rajesh P. Formulation and evaluation of mouth dissolving tablet for the antihypertensive drug. Pharmagene 2013;1:10-20 